ISSN: 0212-0267

DOI: http: //dx.doi.org/IO.I420I/hedu201938155177

\title{
EL JUEGO POPULAR DE LAS CUATRO ESQUINAS: 30 VARIANTES PARA RECUPERAR SU USO EN LA EDUCACIÓN DEL SIGLO XXI
}

\section{The popular four corners game: 30 variants to regain its use in IIst century education}

Jordi Brasó Rius

Universidad de Barcelona

Correo-e: jbrasorius@ub.edu.

Xavier Torrebadella Flix

Universidad Autónoma de Barcelona

Correo-e: xtorreba@gmail.com

Recepción: 9 agosto de 20I8. Envío a informantes: is de septiembre de 2018 Aceptación definitiva: 2I de noviembre de 2018

RESUMEN: La recuperación de la memoria histórica tiene que ser en la sociedad del siglo xxi una prioridad si no se quiere perder la identidad. En esta línea, el objeto de estudio del presente trabajo es el juego popular de las cuatro esquinas. Concretamente se pretende mantener viva esta actividad lúdica y que queda borrada en las mentes de la juventud. Para ello, y a partir de una metodología centrada en el análisis de las principales obras escritas, en torno al siglo XIX e inicios del Xx se asientan las bases para proponer modificaciones. A partir de aquí, y como resultado, se proponen 30 variantes del juego.La finalidad es ofrecer un ejemplo de las múltiples opciones, en este caso de las cuatro esquinas, para mantener viva la llama de la tradición, aunque adaptándola a la actualidad.

Palabras Clave: cuatro esquinas; educación; escuela; folklore; juego.

ABSTRACT: The recovery of historical memory has to be a priority in 2Ist century society if you do not want to lose your identity. In this line, the object of study 
of this work is the popular game of the four corners. Specifically, it is intended to keep this playful activity alive and that it is erased in the minds of the young. To this end and based on a methodology focused on the analysis of the main written works, around the nineteenth and early twentieth century, the bases are established to propose modifications. From here, and as a result, we have developed 30 variants of the game. The purpose is to offer an example of the multiple options, in this case of the four corners, to keep alive the flame of the tradition, although adapting it to the present day.

KEY WORDS: four corners; education; school; folklore; game.

Los juegos tradicionales no han sido considerados más que en la medida en la que podían ser preparatorios para juegos más nobles, que serían los deportes institucionalizados ${ }^{\mathrm{I}}$.

\section{Introducción}

$\mathrm{E}$ L ESTUDIO DE LAS TRADICIONES Y EL FOLKLORE permite a una sociedad no perder su identidad. Y en el siglo xxi, donde conceptos como los de cambio, renovación, innovación, creatividad... cogen su máxima fuerza, no parece que esta tradición tenga una muy buena vida. Es más, los posibles beneficios que pueda haber en la sociedad actual implican el olvido de una (gran) parte de nuestra historia. En este sentido, una parte de esta memoria histórica la forman los juegos tradicionales, que, sin excepción, van olvidándose, perdiéndose, un poco más en cada generación. De este modo, de la mano de los deportes de masas -que parece que son los únicos que se pueden practicar-surgen fenómenos como los de los videojuegos o los e-sports que parecen ser una antinomia de esta tradición jugada ${ }^{2}$. Si las características políticas de la sociedad liberal y económica no han ayudado en la supervivencia del elemento tradicional y folklórico (lúdico), los espacios donde viven los potenciales practicantes de estos juegos van reformándose, configurándose... creando, en definitiva, espacios con características bien diferentes a los de hace unos tiempos. Surgen así espacios que limitan el propio elemento lúdico tradicional:

Los hombres han construido ciudades que prohíben los juegos de los niños. Han suprimido los terrenos libres, superpoblado los patios de las escuelas, asfaltado

\footnotetext{
1 Schmitt, A.: «Prólogo», en Guillemard, G.; Marchal, J. C.; Parent, M.; Parlebas, P. y Sснмiтt, A.: Las cuatro esquinas de los juegos, Lleida, Agonos, 1988, pp. 7-18, p. I2.

2 MartonciK, M.: «E-Sports: Playing just for fun or playing to satisfy life goals?», Computers in Human Behavior, n. 48 (2015), pp. 208-2II; Rambusch, J.; Jakobsson, P. y Pargman, D.: «Exploring E-sports: A case study of game play in Counter-strike», en AkIRA, B. (ed.): Situated play: The 2007 world conference of Digital Games Research Association, Tokio, Digra, 2007, pp. I57-I64; TAYLOR, T.: Raising the Stakes, London, MIT Press, 2012.
} 
EL JUEGO POPULAR DE LAS CUATRO ESQUINAS: 30 VARIANTES PARA RECUPERAR SU USO EN LA EDUCACIÓN DEL SIGLO XXI JORDI BRASÓ RIUS Y XAVIER TORREBADELLA FLIX

las calles y las plazas públicas, invadidas por los automóviles, y han construido grandes edificaciones, especie de vestuarios de individuos que, lejos de ser lugares propicios para favorecer los intercambios y los juegos, son literalmente su antítesis³.

De este modo, los juegos se han regularizado, limitado, controlado..., los adultos han creado espacios artificiales y «óptimos» para su práctica-para la preparación, pero del juego del adulto... no del niño-, pero donde al cabo y al fin «la imaginación se desespera» ${ }^{4}$ los niños acaban abandonando el juego. Así, hay multitud de prácticas para los niños que van olvidándose por esta artificialidad y control permanente.

Por lo tanto, con la recuperación de los juegos populares y su práctica se pretende hacer frente a la hegemonía -en términos gramiscianos- ${ }^{-}$de estos grandes deportes institucionalizados, de masas... y que aparecen en los círculos de amigos, en la familia, en los medios, en la educación... en todos los sitios y a todas horas. Se pretende, por lo tanto, potenciar una nueva educación, crítica, alejada de esta dominación y que tiene en el fútbol y en los e-sports, cada vez más, su máxima representación. En definitiva, se busca y se pretende un movimiento contrahegemónico que permita un mejor conocimiento del pasado de cada uno. Con este no-olvido folklórico, y la recuperación de lo que se ha escondido en la sociedad del siglo xxI, el ser humano podrá hacer frente, relacionar y convivir con el presente y el futuro, sin olvidar sus orígenes. En este sentido, Gramsci, hablando del folklore, apuntaba que su conocimiento era necesario, y que había que investigarse más y más profundamente. Además, tendría que servir para formar una «nueva cultura en las grandes masas populares» ${ }^{6}$. Con esta idea se ha hecho esta pequeña aportación, que ayuda, en palabras, gramscinianas, a hacer desaparecer «la separación entre cultura moderna y cultura popular o folklórica»?

Como consecuencia, el objeto de estudio es el juego de las cuatro esquinas, también conocido con otros nombres: candela, con-con, Sevilla, casita casquila, hay feu, pedir candela...8. Concretamente, se hace un análisis de su aparición a

Schmitt, A.: «Prólogo», en Guillemard, G.; Marchal, J. C.; Parent, M.; Parlebas, P. y Sснмітт, A.: op. cit., p. 9.

4 Ídem, ibidem.

Gramsci, A.: La alternativa pedagógica, Barcelona, Hogar del Libro, i985.

Gramsci, A.: op. cit., p. 295 .

Ídem, ibidem.

8 También es nombrado: quatre cantons, amaga esquenes, pilarets de foc en los Países Catalanes, y candelita en Venezuela. Consultar: Casanova, E.: «La presència de la tradició lexicogràfica valenciana en el diccionari normatiu valencià (DNV): l'exemple del vocabulari valenciano-castellano de Cabrera (1868/1899)», Anuari de Filologia, n. 4 (2014), pp. 23I-275; Gimnástica del Bello Sexo. Ensayos sobre la educación física de las jóvenes, Londres, Ackermann, I827; López, F.: Colección de Juegos para niños de ambos sexos, Madrid, Imp. Antonio Pérez Dubrull, i855; Maspons, F.: Jocs d'Infants, Barcelona, Barcino, I933; PELEgrín, A.: Juegos y poesía popular en la literatura infantil y juvenil (1750-1987), tesis doctoral, Madrid, Universidad Complutense de Madrid, Facultad de Filología, I992; Pelegrín, A.: «Lírica y juegos populares en Gaspar de los Reyes. De la canción de amor medieval a las soleares: profesor Manuel Alvar "in memorian”", en Actas del Congreso Internacional "Lyra minima oral III», Sevilla, Universidad de Sevilla, 2004, Pp. 24I-268. 
través de los principales libros de juegos de los siglos XIX e inicios del xx. Este análisis cimenta la base para una segunda aportación en este trabajo: la creación de diferentes variantes de la práctica para hacerla más diversa, rica y, en definitiva, aplicable a más situaciones de la actualidad. Con ello se contribuye a mantener vivo un juego popular desconocido por gran parte de la juventud del siglo xxI. La metodología se ha basado en un análisis de las fuentes primarias, disponibles en diferentes bases de datos -Hemeroteca Digital de la Biblioteca Nacional de España; Biblioteca Virtual de Prensa Histórica, del Ministerio de Educación, Cultura y Deporte; Google Libros- ${ }^{-}$. Para la búsqueda de estas obras se han tenido en cuenta los estudios y catálogos bibliográficos especializados en la materia ${ }^{10}$. Asimismo, las obras se han ordenado principalmente de manera cronológica a fin de visualizar las evoluciones temporales en las descripciones. Posteriormente, por lo que respecta a las propuestas de variantes del juego, se ha tenido en cuenta el modelo praxiológico motriz de Pierre Parlebas ${ }^{I I}$. Los resultados ofrecen diferentes modos de acercar la tradición al joven ciudadano del siglo xxI y, a la vez, se incita a reflexionar para aportar otras y nuevas variantes, tanto de este juego como de cualquier otro.

\section{El simbolismo del juego de las cuatro esquinas}

Aunque para entender la dinámica de un juego es necesario analizar sus normas, sus indicaciones y su lógica interna, también es básico analizar su lógica externa, es decir, su entorno. Y el juego popular de las cuatro esquinas ha sido comparado con numerosos elementos sociales, místicos, jerárquicos... Como consecuencia, estos simbolismos parece que tienen más fuerza y están más presentes en la sociedad que el propio juego. Por ello, y antes de entrar en analizar la práctica, esbozamos esta aparición literaria y mental del juego.

En primer lugar, y a modo de anécdota, el juego toma un fuerte simbolismo en la medida que se relaciona con la sociedad, donde:

La nobleza, el clero, la administración o los funcionarios públicos, y la clase media estaban cada cual, en su esquina, y el pueblo estaba en medio, como esperando continuamente, aunque en vano, que un pequeño cambio entre estas cuatro potencias le facilitase los medios de modificar y de mejorar un poco su posición.

9 Juntamente con la búsqueda en las propias bibliotecas de libros antiguos de los autores de este escrito.

1o PAstor, J. L.: Educación física y libros de texto en la España contemporánea (I883-1978), Alcalá, Universidad de Alcalá, 2004; Pelegrín, A.: 1992, op. cit., Torrebadella, X.: Contribución a la bistoria de la educación física en España. Estudio bio-bibliográfico en torno a la educación física y el deporte (I800-1939), tesis doctoral, Lleida, Universitat de Lleida, 2009.

" Parlebas, P.: Le destin des jeux: Héritage et filiation. Socio-Anthropologie, n. I3 (2003), pp. I-9; Parlebas, P.: «El destino de los juegos: herencia y filiación», en LAgardera, F. y Lavega, P. (coords.): La ciencia de la acción motriz, Lleida, Universitat de Lleida, 2004, pp. 59-76. 
EL JUEGO POPULAR DE LAS CUATRO ESQUINAS: 30 VARIANTES PARA RECUPERAR SU USO EN LA EDUCACIÓN DEL SIGLO XXI

JORDI BRASÓ RIUS Y XAVIER TORREBADELLA FLIX

Este estado de cosas todavía no ha cambiado, y regularmente aun durará mucho tiempo, si es que no sigue hasta el fin de los siglos ${ }^{12}$.

Destaca también el simbolismo que en Los juegos de la infancia se detalla y se relaciona con la vida misma:

Es un juego que os divierte mucho, mis queridos niños; pero ignoráis aún que tal juego es fiel imagen de lo que pasa en la vida. Para conquistar una posición que se desea, un puesto que se envidia, un favor que se solicita, hay que estar, como Berta, acechando la ocasión. También sucede en la vida, como en este juego, que por querer cambiar de puesto se pierde el que se tenía. Y si se quiere volver al que se dejó por haber llegado tarde al que se pretendía, se le encuentra ocupado ${ }^{13}$.

Asimismo, Antonio José Pérez ${ }^{14}$ detalla la aparición del juego desde esta perspectiva, en numerosas obras literarias. Sucede así en Escenas matritenses-I842-; en la novela Ángel Guerra -I891- y en Cánovas -I912-, de Benito Pérez Galdós; en Malvaloca, de Álvarez Quintero -I954-; en la publicación satírica El padre Cobos -I854-; o incluso en la obra las cuatro esquinas -I980-, de Gianni Rodari. También Vargas Llosa, trata el simbolismo del juego, relacionándolo con el Paraíso, inalcanzable por el género humano. Este Paraíso, por cierto, también aparece como lo que hay que conseguir en otro juego popular como es el de la rayuela ${ }^{15}$. Así, se evidencia la aparición de un simbolismo que la lógica interna y el nombre del juego facilitan. Y se establecen relaciones y comparaciones con la vida, con la sociedad, con el misticismo:

La esquina, el rincón de calles y plazas, son, intuimos, poéticos sustitutos de los confines del mundo, de los puntos cardinales de la Tierra, de los límites del lugar donde el ser humano persigue su destino vital. A estos significados connotativos de la esquina, el rincón, debe sumarse el hecho de que cualquier lugar que en un juego desempeña el papel de casa, de refugio, de zona de descanso en el trajín de la diversión y está transmitiéndonos la expresión lúdica de la necesidad que tiene el ser humano de alcanzar un espacio donde descansar, donde encontrar protección alojamiento y acogida ${ }^{16}$.

12 Fernández, Á.: Los juegos de las diferentes edades, en todos los pueblos del mundo, desde la antigüedad más remota hasta nuestros días. Primera Serie. Juegos y diversiones de la infancia y de la juventud, Madrid, Biblioteca Universal, I85I, p. I4.

13 UN PAPÁ: Los Juegos de la Infancia, Paris, Garnier Hermanos, I897, pp. 19-20.

${ }_{14}$ Pérez, A. J.: «Juego y tradición folklórica en una novela de Mario Vargas Llosa», Olivar, n. I8 (2012), pp. I-I9.

is Brasó, J. y Torrebadella, X.: «Anàlisi i classificació dels jocs de la infància de Joan Amades en funció de la seva lògica interna i del gènere dels practicants (I674-1947)», REIRE. Revista d'Innovació $i$ Recerca en Educació, v. 8, n. 2 (2015), pp. I8-42; BRAsó, J. y COLLELL, X.: «El joc popular de la xarranca. Estudi a través dels llibres i del folklore català. Possibles aplicacions en l'àmbit escolar». REIRE. Revista d'Innovació $i$ Recerca en Educació, v. 9, n. 2 (2016), pp. 82-IO5.

${ }_{16}$ PÉrez, A. J.: «Juego y tradición folklórica en una novela de Mario Vargas Llosa», Olivar, n. ${ }^{\circ}$ I8 (20I2), pp. I-I9, p. I2. 
Finalmente, estas relaciones lúdicas se encuentran también internas en la práctica del juego. Joan Amades, folklorista, detalla que el juego de las cuatro esquinas -en sus palabras: movido y divertido- ${ }^{17}$, aunque practicado principalmente por los niños, también era ejercido por jóvenes y adultos. Principalmente, este hecho se producía en determinadas festividades, romerías y encuentros donde aparece multitud de gente. Incluso, detalla Amades que en Crespià -población gironina de la comarca del Pla de l'Estany- se jugaba después de haber vuelto del Santuario del Mont ${ }^{18}$. En concreto, solo podían jugar aquellos que habían hecho toda la caminata de ocho horas. La idea parece que era gastar al máximo la poca energía que les quedaba, motivo por el cual el juego se practicaba no solamente corriendo, sino también saltando -la parroquia del pueblo beneficiaba a estos héroes con un porrón de vino-. Encontramos, por lo tanto, una primera variante motriz del juego.

Se hace evidente que el juego está envuelto de todo un conjunto de tradición y folklore que lo convierten en parte de la cultura de un pueblo. Así sucede, también, con la mayoría prácticas folklóricas. Por todo ello, la impregnación del juego en los diferentes elementos de la cultura hace, ahora sí, que pasemos a analizar la práctica motriz propiamente dicha -clasificado incluso como juego de persecución-19 la cual nos dará detalles también de la lógica interna de la actividad, de la dinámica del juego y de los espacios de movimiento -elementos que se relacionaron obviamente con este valor simbólico analizado-.

\section{Las cuatro esquinas: descripción del juego a través de los textos}

En la publicación Lícito Recreo ${ }^{20}$ el juego se nombra De las Esquinas. En él se destaca que es un juego de ejercicio y «bueno para aplacar el frío» ${ }^{2 \mathrm{I}}$. Se describen a la vez las normas principales:

Para jugarlo se ponen en una sala grande diez, doce ó mas personas de distancia en distancia proporcionada, á no estar demasiado juntos, porque entonces no habría diversión, y sería difícil que el que se hallase en medio lograse salir jamás; lo menos que ha de haber son tres o cuatro pasos de unos á otros.

Señalados los puestos, y colocados de pie en ellos, uno que salga á la suerte, ó que voluntariamente se ponga en medio, pide fuego valiéndose de estas palabras:

¿Vecina, hay candela?

Todos responden: Allá humea.

Y en este tiempo todos mudan de lugar con prontitud, y el que está en medio procura colocarse en alguno de aquellos puestos que desamparan, y en llegando á

Amades, J.: Costumari Català, Barcelona, Salvat, 1983, v. I, p. 864.

8 Amades, J.: op. cit., v. 5, p. 38.

19 Pelegrín, A.: 1992, op. cit.

${ }^{20}$ Aficionado: Lícito recreo casero, ó coleccion de cincuenta juegos conocidos comunmente con el nombre de juegos de prendas, Madrid, Imp. Ramon Ruiz, I792.

${ }^{21}$ Aficionado: op. cit., p. 92. 
EL JUEGO POPULAR DE LAS CUATRO ESQUINAS: 30 VARIANTES PARA RECUPERAR SU USO EN LA EDUCACIÓN DEL SIGLO XXI JORDI BRASÓ RIUS Y XAVIER TORREBADELLA FLIX

lograrlo, el que se queda sin sitio paga prenda, y se pone en medio, y así se repite hasta que acomode ${ }^{22}$.

Es curioso destacar que se limita el campo a un espacio bien reducido, de unos tres o cuatro metros de lado. Esta distancia, por lo tanto, será uno de los primeros y principales elementos variables para modificar el juego.

Las cuatro esquinas era un juego que gozaba de gran popularidad a finales del s. XviII y durante el s. XIX. Este hecho ya lo destacan Amar y Jauffret ${ }^{23}$ en $L a$ gimnástica ó escuela de la juventud-detallan que esta popularidad era compartida con el juego de La gallina ciega-. Vicente Naharro ${ }^{24}$ detalla también este aspecto popular y habitual del juego, y destaca la posibilidad de que juegasen a la vez ambos sexos [Imagen I]. Quizá por esta última característica, estas actividades gozaban de gran popularidad y eran tan habituales, en una época donde la sexualidad, guiada por un cristianismo autoritario, era un tema tabú. Dichos juegos eran de bien seguro los pocos momentos y espacios donde podían convivir ambos sexos con total libertad-.

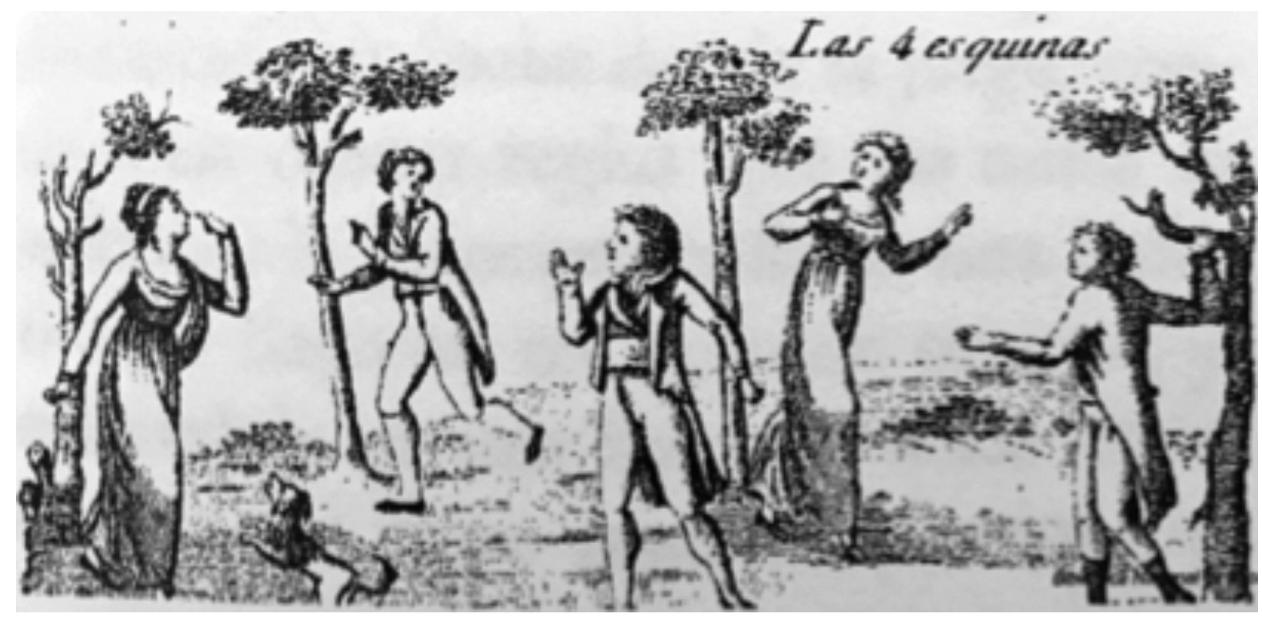

IMAgen r: Práctica del juego de las cuatro esquinas por ambos sexos ${ }^{25}$.

Por lo tanto, y de bien seguro por el bajo contacto entre participantes, el juego era óptimo para las hembras. Este hecho aparece de nuevo reflejado en la Gimnástica del bello sexo [Imagen 2]. Teniendo en cuenta que la obra no pretende «proponer a nuestras discípulas el ejemplo de las doncellas espartanas» ${ }^{26}$, pero

Aficionado: op. cit., pp. 92-93.

23 Amar, J. y Jauffret, L.: La gimnástica ó escuela de juventud, Madrid, Imp. de Álvarez, I807.

24 Naharro, V.: Descripción de los juegos de infancia, los mas propios a desenvolver sus facultades físicas, morales, y para servir de abecedario gimnástico, Madrid, Imp. que fue de Fuentenebro, I8I8.

${ }_{25}$ Naharro, V.: op. cit, p. 57.

26 Gimnastica del Bello Sexo. Ensayos sobre la educación física de las jóvenes, op. cit., p. I8. 
queriendo educar acertadamente, propone diferentes prácticas, como es La candela o las cuatro esquinas, "que no se puede jugar sin correr, y que por consiguiente no está fuera de lugar al frente de este artículo» ${ }^{27}$. Y también es destacable la opinión según la cual, con el juego de las cuatro esquinas se consigue que «entren las chicas en calor ${ }^{28}$, muestra por lo tanto evidente de la pertinencia en el juego por parte del sexo femenino.

En esta línea destaca también el grabado en Minerva de la juventud (I833) [Imagen 3], por parte de Vargas Machuca, y en el que queda evidente la feminidad de la práctica y evidencia los sacrificios que las mujeres tendrán que hacer.

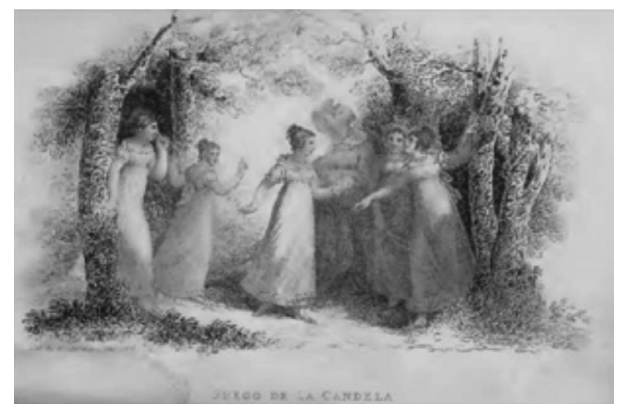

IMAGEN 2: Grabado del juego de La candela².

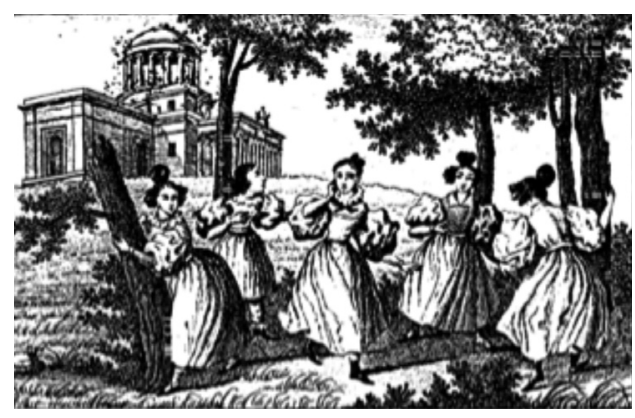

IMAGEN 3: A pie de grabado se afirma: «Sed felices un día porque os están reservadas muchas penas y dolores» $3^{\circ}$.

Esta práctica para todo el mundo -niños, niñas, hombres, mujeres-, juntamente al hecho del no requerimiento de ningún material, hace entender que las cuatro esquinas estuviese descrito en multitud de textos. Otro ejemplo es en el nuevo Manual Completo de Juegos de Tertulia y de Prendas ${ }^{31}$, se describe el juego de las cuatro esquinas. Posteriormente, con el mismo texto, se encuentra la obra de Rementería -ambas, por cierto, son una copia de la obra francesa de Celnart $^{32}$, donde aparece el juego de Les quatre coins- y ya detalla que:

En este juego no pueden entrar sino cinco personas; y cuando sea mucha la concurrencia, se multiplican las partes de las cuatro esquinas. Este juego, aunque puede hacerse en una habitación, se acomoda mejor por su turbulencia á un jardín ó campo; pues los árboles, presentando muchos puntos de apoyo, permiten jugar á gran número, y aumentan la visualidad ${ }^{33}$.

27 Gimnástica del Bello Sexo. Ensayos sobre la educación física de las jóvenes, op. cit., p. $2 \mathrm{I}$.

28 Flores, A.: Ayer, boy y mañana, Madrid, Montaner y Simón, I892, p. 9I.

29 Gimnástica del Bello Sexo. Ensayos sobre la educación física de las jóvenes, op. cit., p. $2 \mathrm{I}$.

30 Pelegrín, A.: 1992, op. cit., p. I079, lámina XCix.

31 Paris, Pillet Ainé, 1836.

32 Celnart, É.: Manuel Complet des Jeux de Société, Paris, Lib. Encyclopédique de Roret, 1836.

33 Rementería, M.: Manual completo de juegos de sociedad o tertúlia y de prendas, Madrid, Imp. de don Norberto Llorenci, I839, p. I8. 
Queda claro pues que, si bien era más pertinente que el juego fuese de exterior, no había ningún problema en jugar en el interior. Por lo tanto, además de la idoneidad del juego para ambos sexos, la popularidad de este venía ayudada también por la posibilidad de practicarse en cualquier terreno y cualquier momento del año. El propio Rementería explicaba detalladamente las normas y dinámica del juego, y sugería consejos:

Se elige un cuadro que tenga cuatro ángulos señalados, ó en su defecto se señalan con una vara hincada en tierra un montón de vestidos, un sombrero, ó una silla. Cada uno se coloca en uno de los ángulos, y el del medio aguarda á que se muden de sitio para apoderarse del que encuentre desocupado. Colocados asi, y hecha la señal de una palmada, empiezan los jugadores á advertirse uno á otro para cambiar de sitio, teniendo cuidado de no perder ni el que dejan, ni aquel á que se dirigen. En este conflicto regularmente coge un sitio, y el que le pierde se coloca en su lugar y vuelve á empezar el juego. Para que este sea agradable, conviene que los jugadores cambien á menudo de sitio, cruzándose á veces en línea diagonal que pase por el centro; porque ir siempre por los lados, es hacerlo monótono, y dar poca acción al del medio. Cuando un jugador después de hacer señas al compañero con quien va á permutar, deja su sitio antes que el otro se haya movido, y el del medio se aprovecha, la justicia pide que el que ha tardado demasiado sea el desposeído; pero para evitar toda disputa tiene autorizado la costumbre que pase al centro aquel cuyo sitio le ha cogido el que antes estaba en él ${ }^{34}$.

También se dan apreciaciones sobre el juego en la obra Juegos de Jardín ó Cam$p o^{35}$, y del mismo modo que Rementería -I839-, se ve óptimo el juego para exterior y también para interior. Por ello se describe todo el procedimiento de juego:

Las esquinas ó puestos en que deben situarse los jugadores, se señalan con un palito, una piedra ú otra cosa semejante, colocadas á dos ó tres pasos de distancia una de otra, bien formando un círculo, ó un cuadrado. Se saca á la suerte el que debe quedarse en medio, y los demás jugadores se colocan en su respectiva esquina. El del medio se dirige á uno de ellos y le dice: Vecinita, ¿me dá V. un poco de lumbre? A lo que le contesta señalando á otra de las esquinas: En aquella casa rebulle. Entre tanto los demás jugadores se hacen señas para cambiar de sitio, que lo ejecutan con prontitud, porque el del medio, atento siempre á estos cambios, procura colocarse en la esquina que halla desocupada, y tiene que sustituirle el que se quedó sin esquina ${ }^{36}$.

También se incide en que son cinco los jugadores que juegan, aunque existe la posibilidad de añadir participantes. Por lo tanto, esta variante ayudaba también a hacer más popular el juego. Se detallan de manera clara las normas del juego ${ }^{37}$.

Apunta el autor que la diversión y vivacidad del juego radica en el hecho que los jugadores de las esquinas cambien a menudo de sitio, incluso en

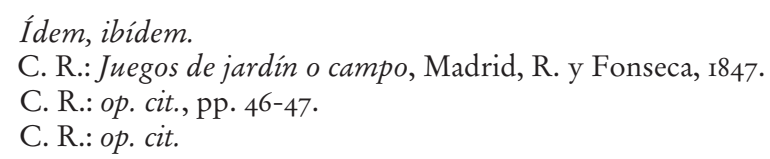


diagonal, teniendo el riesgo de perder una esquina y tener que ocupar el lugar del medio.

Esta remarcable popularidad se puede entender también analizando la obra Los juegos de las diferentes edades, donde se comenta que «todos los que han sido jóvenes, y de seguro lo han sido todos los viejos, conocen el juego de las cuatro esquinas $»^{38}$. Se describe como actividad generalmente en la naturaleza donde los árboles hacen de esquinas. Además, se dan indicaciones del juego apuntando que, si no hay una voluntad de arriesgar y de engañar, la actividad resulta aburrida y monótona. Se comprueba también la posibilidad-variante de adaptar el juego a los participantes concretos:

Como una sociedad encuentre en un bosque, en un jardín, sobre el verde césped, es muy raro que no se entregue al bonito juego de las cuatro esquinas. Solo pueden jugar cinco personas; pero en un bosque, cuando la sociedad es numerosa, es fácil multiplicar las partidas de las cuatro esquinas. En tal sitio nunca faltan árboles, y como presentan muchos puntos de apoyo, puede jugar mucha gente a la vez, aumentando infinitamente la diversión. Uno de los jugadores se sitúa en medio de los otros cuatro, que se hallan en cuatro esquinas, es decir, junto a cuatro árboles distantes igualmente uno de otro en forma de cuadro. Estos últimos cambian de sitio con los del cuadro inmediato. Mientras dejan su puesto para tomar el de otro, el del medio trata de apoderarse de un lugar abandonado. El que no encuentra sitio se queda en el medio. Para que el juego sea agradable conviene que los jugadores cambien frecuentemente de sitio, haciéndolo a veces con los de la esquina opuesta, esto es corriendo en línea diagonal o formando cruz entre los de las cuatro esquinas. Nada sería mas monótono que cambiar siempre de sitio con el que se halla enfrente: andando solamente por el camino más corto no le dejarían bastantes probabilidades de conseguir un sitio al que se hallase en el medio. Suele suceder que un jugador, después de haber hecho señas a otro para que se venga a su sitio, y aun después de dar algún paso hacia delante, muda de parecer repentinamente y se queda en él, haciendo que el otro pierda el suyo y sufra un desengaño. En este caso, la justicia mandaría que el que había tardado se quedase en el medio en vez del que le había creído. Pero en los juegos, como en todas las cosas, se desconoce la justicia con mucha frecuencia, y el engañado tiene que tomar su partido. A su vez puede vengarse ${ }^{39}$.

Analizando esta posibilidad de variar el juego para adaptarlo al número de jugadores, López ${ }^{40}$ describe su reglamento y dinámica de modo claro y sencillo. Asimismo, vuelve a aparecer esta idoneidad de la práctica para ambos sexos. A diferencia de Fernández ${ }^{41}$, en este caso destaca el juego como actividad de interior. De todas formas, ello no impide variar el juego al número de jugadores. López destaca el dialoguillo-cancioncilla que forma parte a menudo de la dinámica lúdica -y femenina-:

38 FernándeZ, Á.: 185I, op. cit., p. I4.

39 FERnÁndeZ, Á.: I851, op. cit., pp. I3-I4.

40 López, F.: I855, op. cit.

${ }_{41}$ Fernández, A.: I85I, op. cit. 
La ejecución es muy sencilla, y, aunque el nombre solo del juego me evitaría dar á las niñas una explicación de él, la daré, sin embargo, por si este librejo llegara á alguna parte donde el tal enredo no se conociere.

Se juega en una habitación cuadrada, y habiendo cinco niñas, se colocan cada una en un ángulo de la habitación, y la sobrante en medio. Si fueren más de cinco las niñas, se improvisan ángulos, colocándose al lado de las paredes en sitios marcados guardando iguales distancias, y en este caso puede también jugarse en el campo. Para ponerse las niñas en sus respectivos puestos, tiene que dar la señal la que queda en medio, diciendo: «Con-con, cada una á su rincón».

Y una vez colocadas, empieza el juego, acercándose la niña sobrante á las otras sucesivamente, y preguntando á la primera: ¿hay candela?; Esta contesta, señalando á la niña que está á su derecha: "por allí humea».

La niña que preguntó se acerca á la otra que le contesta lo mismo, é igualmente á todas las demás, de quienes obtiene la misma contestación.

Mientras va recorriendo así á todas y preguntando si hay candela, las niñas que están en sus puestos se convienen unas con otras para medio de una seña, procurando no ser vistas de la que va preguntando, y cambian de sitio con ligereza para no dar lugar á que aquella se adelante á coger uno, y se quede una de ellas sin esquina, en cuyo caso pierde, diciendo la que le tomó su puesto: «Quien fue á Sevilla perdió su silla».

Debe la niña que va recorriendo los puestos prestar mucho cuidado y atención á las otras, observando con disimulo las señas que se hagan para robarles los sitios.

Hay en este juego lances raros, pues muchas veces, al partir una niña de su puesto para colocarse en el de la compañera con quien se ha convenido, sucede que una tercera quiere cambiar también, y marcha á ocupar el sitio que deja la primera; la niña que anda recorriendo los puestos, al ver esto, marcha á ocupar el sitio que dejó la tercera; entonces la segunda se queda sin moverse del suyo, y la primera se encuentra con que tiene que quedarse su sitio y recorrer preguntando si hay candela ${ }^{42}$.

La pertinencia del juego en ámbitos femeninos se vuelve a hacer evidente en «tan conocido juego» ${ }^{43}$. Asimismo, destaca el autor que el origen de la práctica «se pierde en la noche de los tiempos, pero que goza siempre de mucha aceptación, y está además reconocido como uno de los más saludables ejercicios para la infancia» ${ }^{44}$. En el texto además de describir la práctica, se proponen tres variantes, una con cinco esquinas y otras dos geográficas; la segunda de ellas, más sencilla, ya que la falta de instrucción de las niñas les impide jugar al primer juego propuesto.

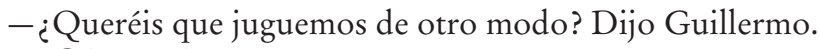

- ¿Cómo, cómo?

- Por geografía.

Las niñas se sorprendieron un tanto.

- ¿Y cómo es eso? Preguntaron algunas.

- Nada mas fácil. Cada uno de nosotros representa una parte del mundo ó un país cualquiera. El que se queda, y se nombra viajero, pregunta por la estension y

42 López, F.: 1855, op. cit., pp. 65-67.

43 García, J.: «Juegos de niñas», Educación Pintoresca, n. 42 (1858), pp. II9-I22, p. II9.

44 Ídem, ibídem. 
demás condiciones del continente que representa á cualquiera de los niños, y si este al contestar comete un error ó equivocación, tiene que ceder su puesto, y ser viajero á su vez.

- [...] Sin embargo, pudiéramos jugar de un modo mas sencillo. Cada uno de nosotros representa una población: el que se queda, y se titula la posta, dice: la posta corre de Madrid á Sevilla, y los dos niños que simbolizan estas poblaciones cambian de puesto, debiendo la posta dejar á uno de los dos sin él. [...]

Continuaron de este modo largo rato, hasta que ya rendidos de reir y correr hicieron alto, dando por terminado el juego, no sin haberle celebrado mucho por lo original, y ofrecido repetirle otras muchas tardes ${ }^{45}$.

Posteriormente, en Los juegos de la primera edad, se detalla también el juego, recalcando la necesidad de buscar un espacio sin obstáculos y con las cuatro esquinas a la misma distancia unas de otras y del centro. Además, se recomienda como óptimo para el trabajo de las fuerzas y como saludable. A la vez, se propone como normativa que el participante que ocupa el centro vaya por las esquinas recitando una pregunta que se repite. A nivel normativo también se propone que los jugadores esquineros cambien todos a la vez de posiciones para incrementar la dificultad del juego. Finalmente, y por lo que respecta a su lógica interna, se ofrece incluso una variante con tres esquinas:

Al llegar los niños una tarde al término de su paseo, con más impaciencia que formalidad, muy sosegados delante de sus padres, quisieron entregarse, mientras ellos descansaban, á uno de los saludables juegos de la infancia. La circunstancia de ser cinco los que habían de jugar, les sugirió la idea de elegir el juego de las cuatro esquinas, que por el movimiento continuo que necesita, es uno de los más convenientes para desarrollar las fuerzas y ejercer saludable influencia en el cuerpo. Anduvieron algún tiempo buscando un sitio que reuniese las condiciones que este juego requiere: un terreno firme y sin estorbos entre las cuatro esquinas ó árboles que han de hacer sus veces, colocados si es posible á distancias iguales como de diez pasos.

- ¿Quién es el que se queda? Preguntábanse los niños unos á otros, porque al empezarse el juego, como que aún no podía haberse sentenciado el que se había de quedar sin esquina, y precisado á ir de una en otra hasta lograr una vacante, era forzoso que alguno fuera el penitenciado. Disponíanse á echar suertes, cuando Victor se ofreció galantemente á quedarse, haciendo este obsequio á las niñas. El juego de las cuatro esquinas, como todos los demás, tiene sus reglas fijas, de que los niños se muestran escrupulosos observadores. Las cuatro esquinas ó árboles deben estar colocados en esta forma:
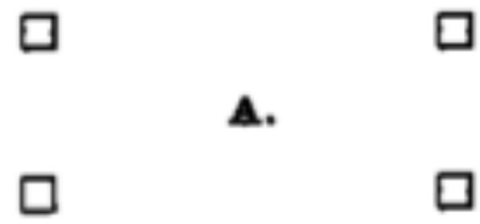

45 Ídem, ibídem. 
Cada árbol estará ocupado por uno de los que jueguen y el punto A por el que se queda, según la espresion vulgarmente usada. El que se queda se dirige á cualquiera de las cuatro esquinas, diciendo:

- ¿Me hace vd. el favor de una ascuita de lumbre?

La persona interpelada, indicándole con el dedo cualquiera de las cuatro esquinas, le contesta:

-En aquella esquinita rebulle.

Así da tiempo para que mientras se dirige á la otra esquina, puedan los jugadores cambiar de sitio, debiendo estar el otro con ojo alerta, para lanzarse al primer sitio que vea desocupado, y entonces el propietario de aquel puesto, si no puede coger otro, tiene que quedarse en el medio y repetir la maniobra de ir de esquina en esquina hasta que logre pillar una. Para animar mas el juego, conviene que todos los jugadores cambien á la vez, resultando en medio de este movimiento general, que dos suelen dirigirse á la vez á la misma esquina, y alguno de ellos se ha de quedar forzosamente plantado en el medio.

Sucedió que Rita se cansó pronto y los demás continuaron el juego con tres esquinas, en esta forma:
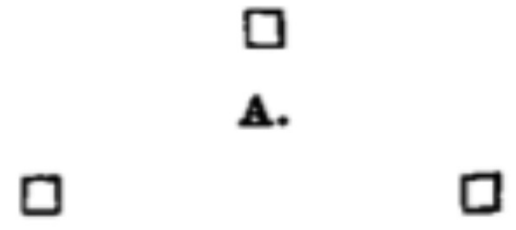

Pero habiéndose luego cansado todos, se sentaron en el suelo a descansar y contar historias ${ }^{46}$.

El carácter femenino destaca también en la obra de Fernández Villabrille ${ }^{47}$, en Juegos y entretenimientos de las niñas, y en la línea de la Gimnástica del bello sexo considera el juego óptimo para las niñas. También destaca la normativa, se recalca su carácter interior o exterior, y a la vez se sugiere la cancioncilla-dialoguillo ${ }^{48}$ que la niña que ocupa el centro tiene que ir haciendo a sus compañeras -estas retahílas han sido estudiadas por Pérez-49:

Las cuatro esquinas han de ser cuatro árboles de un jardín o los cuatro ángulos de un aposento. Las niñas que juegan han de ser cinco. Cuatro se colocan en las cuatro esquinas y la que se queda se coloca en el centro. Esta se acerca a una de las niñas ya colocadas en los ángulos y le dice:

${ }_{46}$ Fernández, F.: Los juegos de la primera edad, Madrid, Est. Tip. de Mellado, I862, pp. 39-42.

47 Fernández, F.: Juegos y entretenimientos de las niñas, Madrid, Imp. del est. de Mellado.

${ }_{48}$ Dialoguillo por cierto citado, como apunta Pelegrín -1994, op. cit.- en los textos y bailes teatrales del Siglo de Oro. Un ejemplo es el recogido por LlorCA -1983-: «-Amo, ¿hay candela? / -A la otra puerta / -Amo, ¿Hay candela? / -Por allí humea»-Pelegrín, A.: 1992, op. cit., p. 199-. Asimismo, en Cataluña el dialoguillo es el siguiente: «-Tita foc / -A s'altra casa n'hi ha un poc»-PELEGRín, A.: 1992, op. cit., p. 199-. La investigadora también cita el dialoguillo catalán que Maspons (I874) escribe: «-Teta de pa i formatge /-Vés-te’n a mal viatge»-Pelegrín, A.: 1992, op. cit., p. IO7-.

49 Pérez, A.: 20I2, op. cit. 
- ¿Me da usted una ascuita de lumbre?

A lo que la otra contesta, señalando el lado opuesto:

-En aquella esquinita rebulle.

Mientras que la que se queda se dirige de un lado a otro, las otras niñas han de cambiar de esquina rápidamente, antes que la que se queda coja un puesto vacío y la que allí estaba tenga que salir al medio ${ }^{50}$.

Es destacable que los árboles como elementos del juego para limitar el espacio y delimitar las esquinas aparecen representados en los grabados. Hacen la función delimitadora que en la práctica del juego en el interior hacen las esquinas de las habitaciones. De todas formas, cualquier elemento es óptimo para el juego -por ejemplo, sillas o sombreros-, a fin de poder jugar.

Por lo tanto, surge el ingenio por encontrar nuevas formas lúdicas para adaptar la práctica al número de participantes y variarla para evitar el aburrimiento. Este será un posible punto de inicio para recuperar el juego en la actualidad. En esta línea, en la publicación periódica La Aurora de la Vidatambién aparece detallado el juego y la posible variante de incrementar el número de jugadores. A la vez, se explica que es posible jugarlo en un lugar cerrado, pero es óptima la recreación al exterior. Asimismo, y a modo de posible variante, destaca el hecho de apoyarse en las paredes u árboles para el juego.Y, también, se destaca la posibilidad de utilizar cualquier material para determinar el terreno de juego, de modo similar a las indicaciones de Villabrille ${ }^{\text {s. }}$.

A la vez, y en la línea de proponer variantes, se dan indicaciones para evitar el aburrimiento. Se propone no estar quieto todo el rato y arriesgarse a hacer cambios en diagonal:

En este juego no pueden entrar sino cinco niños, y cuando haya mayor número, se salva el inconveniente multiplicando las partes de las cuatro esquinas.

Este juego, aunque puede hacerse en una habitación, se acomoda mejor por su movimiento á un jardín ó patio, pues los árboles ó ángulos de las paredes, presentando muchos puntos de apoyo, permiten jugar á gran número y aumentar la visualidad.

Se elije un cuadro que tenga los cuatro ángulos señalados, ó en su defecto se señalan con una vara clavada en tierra, un sombrero, una silla ó cualquier objeto que convenga.

Cada uno se coloca en uno de los ángulos, y el del centro aguarda á que se muden de sitio para apoderarse del que encuentra desocupado. Colocados así y hecha la señal, una palmada, empiezan los jugadores á cambiar de sitio, teniendo cuidado de no perder ni el que dejan ni aquel á que se dirigen. En este conflicto, regularmente coge un sitio el de en medio, y el que pierde se pone en lugar de aquel, y vuelve á empezar el juego. Para que este sea agradable, conviene que los jugadores cambien á menudo de sitio, cruzándose á veces en línea diagonal, que pase por el centro; porque ir siempre á los lados, es hacerlo monótono y dar poca acción al del centro.

so FernándeZ, F.: I864, op. cit., pp. 25-26.

si Fernández, F.: I864, op. cit. 
Cuando un jugador después de hacer seña al compañero con quien vá á permutar, dejara su sitio antes que el otro haya movido, y el del centro se lo quita, la justicia pide que el que ha tardado demasiado sea el desposeído; pero para evitar toda disputa, tiene autorizada la costumbre que pase al centro aquel cuyo sitio halla ocupado.

Este juego es propio de ambos sexos ${ }^{22}$.

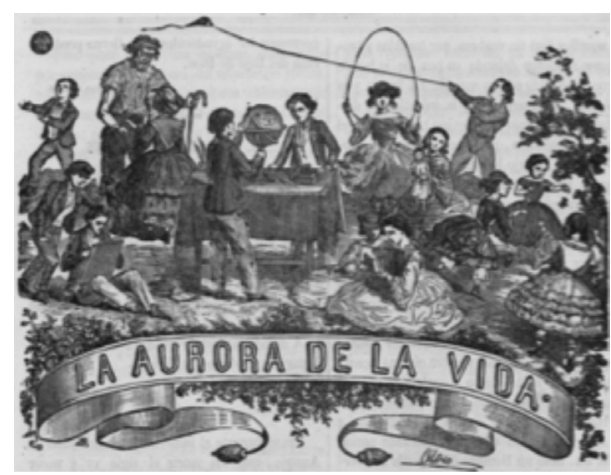

Imagen 4: Portada de la revista La Aurora de la Vida. Se pueden visualizar numerosos juegos, juguetes y actividades de ocio de los niños ${ }^{53}$.

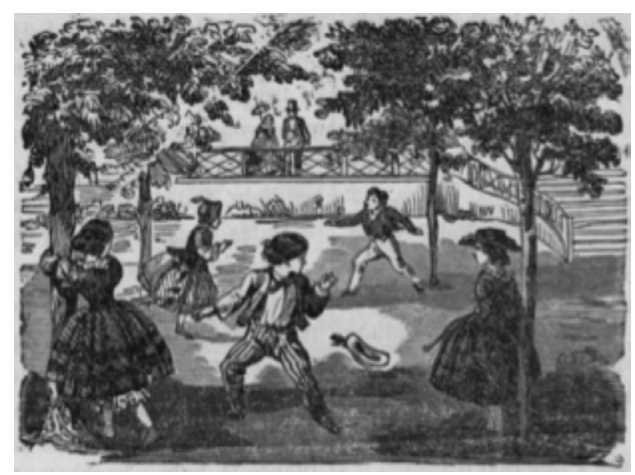

IMAGEN 5: El juego de las cuatro esquinas con cuatro árboles como delimitadores de la práctica. Se intuye que los niños participantes son de clase media-alta -viendo cómo visten-, y con la mirada atenta de dos adultos de la burguesía ${ }^{54}$.

Esta posibilidad de jugarse en lugar cerrado o al exterior, como se ha ido viendo, es también analizada por el padre Santos. Destaca, además, que las cuatro esquinas, entre otras prácticas lúdicas, es un juego que permite dividir a los alumnos de una clase por niveles de fuerza y habilidad. Incide el autor también en que su nombre se refiere a los cuatro ángulos de las paredes de una habitación. Asimismo, destaca la variante de añadir más esquinas, la normativa de salir de la esquina de forma regular y el hecho de variar el juego en espacios pequeños con un desplazamiento a pata coja:

Cuando se juega en el campo o en los sitios de recreo la falta de rincones se suple con árboles, columnas, etc., o sencillamente con circunferencias trazadas en el suelo. No hay tampoco dificultad alguna en que sean más de cuatro los sitios elegidos.

El juego es bien sencillo. En el centro del sitio o en otro algo distante se reúnen los jugadores, uno más que el número de puestos elegidos. Uno cualquiera dice: con, con, cada uno a su rincón, y se lanzan a ocupar puesto. El que se queda sin él va al centro y da una palmada; comienzan los demás a cambiar de sitio unos con otros, y él se aprovecha, si puede, de estos cambios para ocupar alguno de los puestos; si lo consigue, le sustituye en el oficio quien se quede sin él.

12 «Las cuatro esquinas», La Aurora de la Vida, v. I, n. 16 (186I), pp. 255-256.

"3 OTERo: «Portada», La Aurora de la Vida, v. I, n. I6 (186I), p. 24I.

54 «Las cuatro esquinas», 186I, op. cit., p. 255. 
Los jugadores pueden volver atrás después de haber salido del sitio, no aceptar el cambio, ocupar el puesto de otro descuidado, etc., a no ser que algunos de estos ardides se excluyan previamente. Nadie puede permanecer sin salir más de uno o dos minutos, o el tiempo convenido, so pena de perder, excepto el caso en que el perseguidor impida la salida.

Cuando el sitio es reducido suelen jugar también corriendo a la pata coja, o de otro modoss.

La variante de añadir más jugadores-esquinas aparece también en El Amigo de la Infancia, donde se acentúa de este modo el aumento de complejidad y de diversión del juego en esta idea. Como peculiaridad, la publicación es una copia casi idéntica de La Aurora de la Vida. Y otra vez aparece, como sucede a menudo en la sugerencia de cambiar las posiciones a menudo y en diagonal, ya que si no: «Nada sería más monótono que cambiar siempre de sitio con el que se halla enfrente, recorriendo solamente el camino más corto, porque no le dejarían bastantes probabilidades de conseguir un sitio al que se hallase en medio» ${ }^{56}$.

Y en una idea saludable, Bastinos recalca la necesidad de prácticas lúdicas higiénicas y educativas: «En toda diversión juvenil debe atenderse á la Higiene en primer lugar, á la Educación en segundo, y en último término, á la Instrucción» ${ }^{57}$. El juego de las cuatro esquinas cumple este requisito, y se incluye en su manual. Destaca el autor la dinámica del juego y la potenciación de la atención que se trabaja:

Para entregarse á la socorrida diversión de las cuatro esquinas no siempre son necesarias éstas y aun en ciertas ocasiones sirven para conseguir testarazos y otras poco agradables sorpresas; recomendamos el procedimiento de las cuatro sillas, puestas formando cuadro, y si se tropieza con ellas, es de este modo el mal menor.

La miga del juego de las cuatro esquinas está en la dificultad que tiene el jugador del centro en vigilar los movimientos combinados de los cuatro contrincantes: en efecto, estos se avisan con la mirada y el gesto, invitándose á cambiar su sitio respectivo, y si en el trayecto ó cambio de esquina, el fulanito del centro puede llegar antes á la esquina momentáneamente desocupada, queda en mitad del arroyo el que no anduvo bastante listo para evitarlo.

Este juego, sin ser complicado ni tener otro inconveniente que el apuntado en otro párrafo anterior, es tan entretenido como propio para aguzar la atención y dar á los movimientos una destreza siempre útil y á veces de vital importancia ${ }^{58}$.

Este aspecto higiénico es, por lo tanto, otro aspecto facilitador de esta popularidad social de la que gozó la actividad y que lo llevó a ser «un juego que conocen todos los niños del mundo» $\$ 9$, tal y como se describe en Los Juegos de la Infancia -I897-, donde además de la posibilidad de práctica para ambos sexos [Imagen 4],

"SAntos, Padre: Juegos de los niños en las escuelas y colegios, Madrid, Saturnino Calleja, I876, p. 24.

«Las cuatro esquinas», El Amigo de la Infancia, v. 7, n. 74 (I880), p. 68.

Bastinos, J.: Juegos Infantiles, Barcelona, Lib. de Antonio J. Bastinos (ed.), I896, p. 2.

Bastinos, J.: i896, op. cit., p. 44.

Un PAPÁ: I897, op. cit., p. I9. 
se destaca la necesaria rapidez de movimientos, y la atención indispensable para poder ganar la esquina:

Cuatro niños se colocan en los ángulos de un cuadrado y cada uno se apoya en un objeto, que suele ser un árbol ó un rincón. Otro niño, el quinto, se coloca en medio del cuadrado, esperando que alguno de los otros quiera cederle el sitio. Pero los otros no están dispuestos a ceder sus posiciones sino a disputarlas. [...] Estos cambios deben operarse tan rápidamente, que la jugadora colocada en medio [...] no pueda si no anda lista apoderarse de cualquiera esquina de las que quedan un instante desocupadas. Algunas veces, la niña o niño que está en medio tarda mucho tiempo en apoderarse de una esquina y es larga su penitencia; pero siempre acaba por descuidarse alguno de los otros y se cuela en su lugar. Entonces le toca la penitencia al que se descuidó, que está de plantón hasta pescar un sitio ${ }^{60}$.

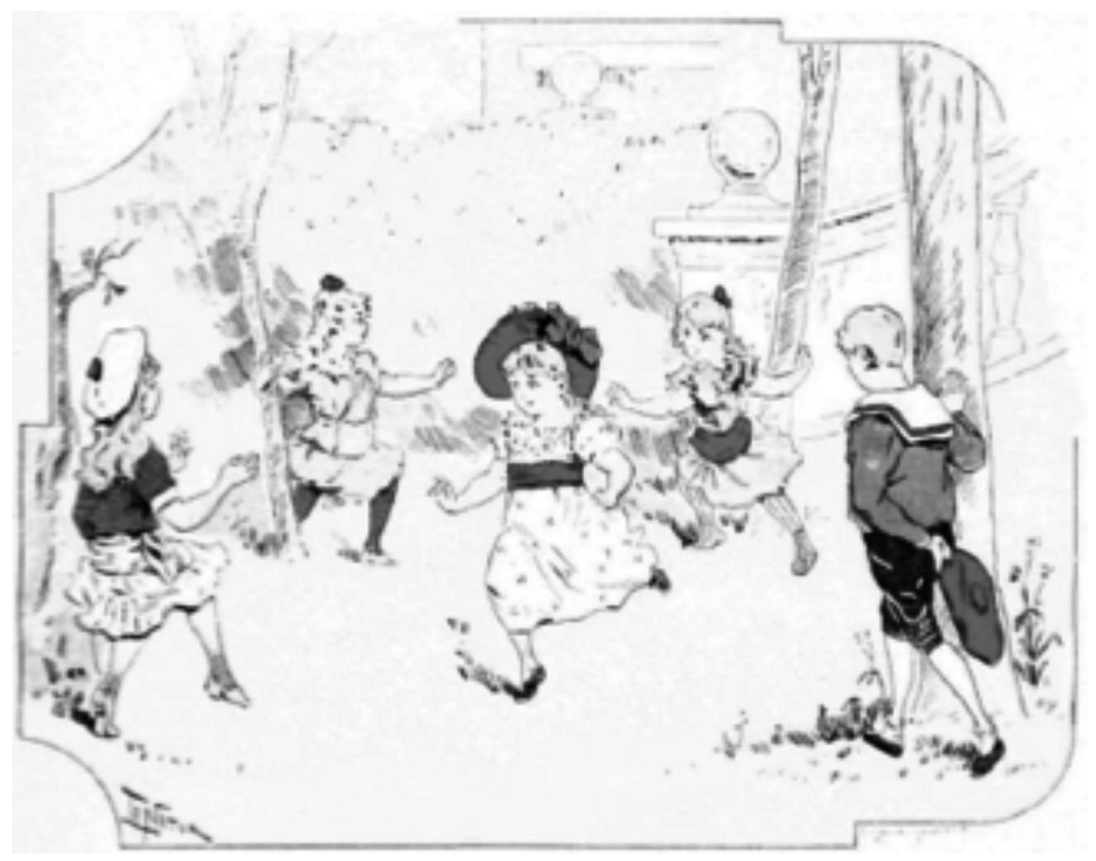

IMAGEN 6: Las cuatro esquinas, practicado al exterior, con los árboles como delimitadores y por ambos $\operatorname{sexos}^{6 \mathrm{I}}$.

Y a esta popularidad evidente, que tiene en los libros su justificación, destacan diferentes aleluyas [imagen 7,8 ], como elementos de la tradición, hecho que refuerza la tesis sobre la significatividad de la práctica en las costumbres de antaño ${ }^{62}$.

60 Un PAPÁ: I897, op. cit., p. 20.

${ }_{61}$ Un PAPÁ: 1897 , op. cit., p. 19.

62 Pelegrín, A.: Juegos y poesía popular en la literatura infantil y juvenil (1750-1987), tesis doctoral, op. cit. 


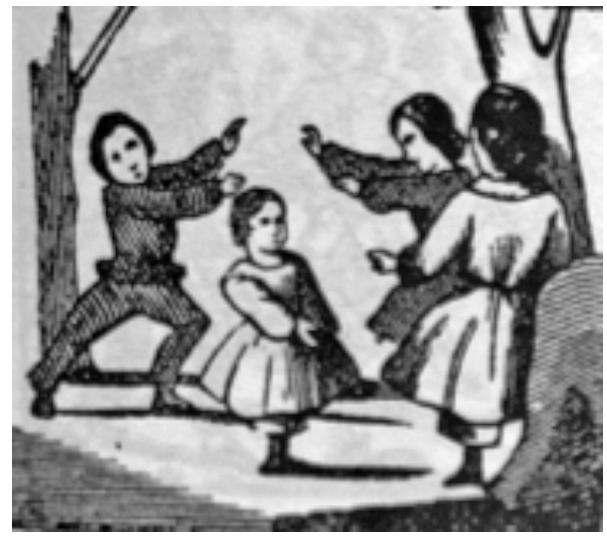

IMAGEN 7: El juego de las cuatro esquinas según una aleluya del siglo $\mathrm{XIx}^{63}$.

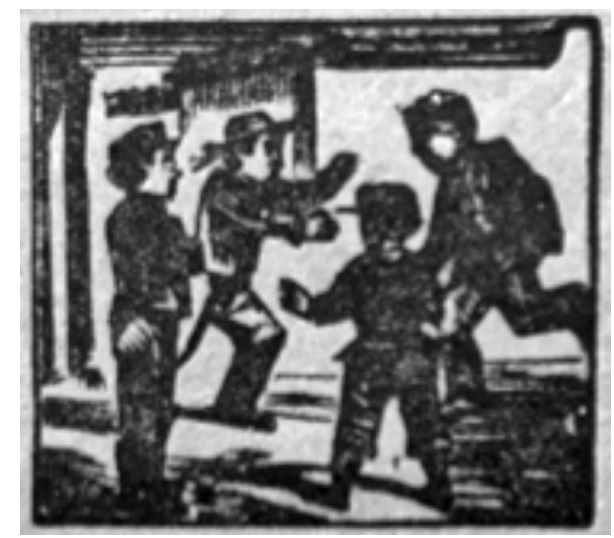

IMAGEN 8: Con el texto: «Las cuatro esquinas es juego de mucho desasosiego» ${ }^{64}$.

Finalmente, y como colofón de esta visita a través de los libros, reproducimos las explicaciones de Schmitt, quien describe cómo aparece el juego de las cuatro esquinas, de manera autónoma en los niños, y la habilidad que algunos jugadores tienen por encima de los otros:

Cada año, cuando llega la época, en un parque grande próximo al colegio se organizan partidas de cuatro esquinas a la salida de las clases, tan sencillamente como si se tratara de continuar un juego interrumpido la víspera. ¿Cómo describir, sin traicionarla, la obra que se representa ante nuestros ojos en el espacio encantado, delimitado rápidamente por tres árboles y una cartera escolar dejada en el suelo? Lo primero que llama la atención es la extraordinaria presencia en el juego de jugadores para quienes ninguna otra cosa parece existir. Completamente absortos en sus ritos, en apariencia indefinidamente recomenzados, los actores, protegidos por invisibles murallas, nos ignoran hasta tal punto que podemos participar en su fiesta sin tener la sensación de molestarles.

El juego de las cuatro esquinas reclama, de hecho, una vigilancia sin fallo. En este pequeño espacio, y contrariamente a otras situaciones en las que la velocidad de desplazamiento interviene más, las distancias reducidas dan una prioridad singular a la necesidad de presentir, de adivinar, de adelantar las intenciones del otro para desbaratar sus movimientos casi en una fracción de segundo. Como en las artes marciales parece que algunos jugadores hayan adquirido ese sexto sentido que da este poder de «sentir» el momento en el que el otro entrará en su campo y no solamente el otro, sino también todos los otros, puesto que hay que tener en cuenta simultáneamente al compañero con el que se «dialoga», al guardián, y a los otros jugadores. Ser cinco y no: uno más uno, más uno, más uno, más uno... es decir, ser capaz de una apertura hacia cada uno sin perderse uno mismo, lo que representa el signo de una personalidad en vías de alcanzar una gran madurez de

63 Amades, J.: 1983, op. cit., v. I, p. 864.

${ }^{64}$ Juegos de la Infancia. Segunda Parte, Madrid, Suc. de Hernando, s. a., n. 98. 
EL JUEGO POPULAR DE LAS CUATRO ESQUINAS: 30 VARIANTES PARA RECUPERAR SU USO EN LA EDUCACIÓN DEL SIGLO XXI

JORDI BRASÓ RIUS Y XAVIER TORREBADELLA FLIX

comportamiento, he aquí lo que parece preparar, entre otras cosas, el juego de las cuatro esquinas.

Así el espectador asiste, si sabe verlo, a un verdadero ballet con actuaciones de lo más inesperadas, en las que todos los actores se ponen en movimiento, con una señal invisible, para una creación constante del conjunto de los participantes ${ }^{65}$.

Se propone, a partir de aquí, una recuperación de las cuatro esquinas a partir de determinar nuevas variantes y formas lúdicas, que partan de esta práctica. Y todo ello nos lleva a no dejar dicha práctica en el olvido; y además de transmitirlo y practicarlo tal y como aparece en la bibliografía consultada, se hace inevitable reinventarlo para utilizarlo como aprendizaje de numerosas habilidades motrices y cognitivas; y en el ámbito educativo, tanto relacionadas con la educación física, como con otras materias.

\section{Análisis praxiológico del juego y 30 variantes educativas}

A través de las obras antiguas se han detallado diferentes variantes del juego para hacerlo más dinámico o para que participase más -o menos- gente. Para su elaboración se ha tenido en cuenta la propia situación motriz de las cuatro esquinas, representada por su lógica interna, es decir, por los elementos que aparecen cuando se practica dicha actividad. De este modo, se pueden comprender «los rasgos “distintivos” que definen la misma acción motriz, dado que las configuraciones, al ser variadas, permiten comparar de manera regular y objetiva los juegos deportivos» ${ }^{66}$. El juego de las cuatro esquinas, como situación motriz que es y analizado bajo su lógica interna, en términos de Parlebas ${ }^{67}$, se define como una actividad con compañeros, adversarios y en un medio estable, por lo tanto, es un juego sociomotriz. Asimismo, según algunas dimensiones de análisis el juego analizado se caracteriza por tener un espacio de juego común y en el que la relación con los participantes es ambivalente, es decir, «un mismo jugador puede cooperar y oponerse simultáneamente respecto a otro», e inestable, o, lo que es lo mismo, que «un jugador puede cambiar de la cooperación a la oposición respecto a otro o viceversa» ${ }^{68}$. A la vez, el juego tiene una disimetría por lo que hace referencia a los dos roles principales: el jugador del medio actúa, en principio, contra todos los otros.

Asimismo, en función de los roles, en el juego analizado aparecen diferentes funciones: defensor de esquinas, atacante de esquinas. Finalmente, en relación con la equilibración motriz y los comportamientos puntuables, estos factores los dan el hecho de ocupar, por parte del participante que está en medio, alguna de las cuatro esquinas.

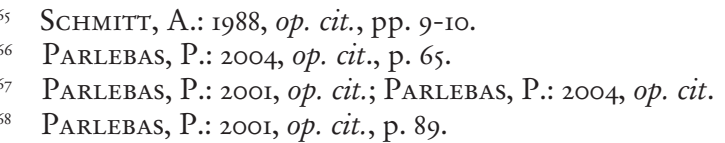


Aunque el análisis paraxiológico podría ser mucho más extenso, estos rasgos principales permiten buscar nuevas formas del juego tradicional. Se proponen 30 variantes -algunas de ellas ya propuestas en los libros analizados y otras relacionadas con otras materias escolares-, aunque es posible descubrir-crear muchísimas otras formas de modificar el juego.

TABla r: Ejemplo de variantes del juego de las cuatro esquinas -elaboración propia a partir del modelo praxiológico de Parlebas- ${ }^{69}$. Se han ordenado a partir de las variables: espacio, móvil, participantes, motricidad, desplazamiento, y para el trabajo de contenidos históricos, matemáticos, geográficos...

\begin{tabular}{|c|c|c|}
\hline \multicolumn{2}{|r|}{ MODIFICACIÓN LÚDICA } & OBSERVACIONES \\
\hline \multicolumn{3}{|r|}{ El espacio } \\
\hline I & Ampliando el espacio & Para trabajar la velocidad general \\
\hline 2 & Disminuyendo el espacio & Para potenciar la velocidad de reacción \\
\hline 3 & Utilizando las esquinas para propulsarse ${ }^{70}$ & $\begin{array}{l}\text { Para poder tener mayor velocidad de aceleración, gracias al empuje } \\
\text { con la esquina (árbol, pared) }\end{array}$ \\
\hline 4 & Modificando el propio terreno & $\begin{array}{l}\text { Aunque no es en sí una variante, se propone el juego en otras super- } \\
\text { ficies: arena, agua o terreno con incertidumbre }\end{array}$ \\
\hline \multicolumn{3}{|r|}{ El móvil } \\
\hline 5 & $\begin{array}{l}\text { Añadiendo un balón -del tipo que sea- } \\
\text { para cada participante }\end{array}$ & $\begin{array}{l}\text { Para potenciar el trabajo técnico del deporte o habilidad motriz co- } \\
\text { rrespondiente, además de entrenar la disociación entre el control } \\
\text { del móvil y la toma de decisiones -bote, conducción con uno o los } \\
\text { dos pies, toque de dedos- }\end{array}$ \\
\hline 6 & $\begin{array}{l}\text { Añadiendo un móvil en el juego para los } \\
\text { participantes de las esquinas }\end{array}$ & $\begin{array}{l}\text { Para potenciar el trabajo del pase, con toma de decisiones. En este } \\
\text { caso se podrían añadir nuevas normas como, por ejemplo, que un } \\
\text { pase erróneo significa ocupar el centro, o también que el jugador } \\
\text { del centro robe el móvil }\end{array}$ \\
\hline 7 & $\begin{array}{l}\text { Añadiendo un móvil solo para el jugador } \\
\text { del centro }\end{array}$ & $\begin{array}{l}\text { La finalidad de esta variante sería básicamente facilitar la tarea a los } \\
\text { participantes de las esquinas }\end{array}$ \\
\hline 8 & $\begin{array}{l}\text { Añadiendo un móvil para el del centro y } \\
\text { con la posibilidad de disparar a quien salga } \\
\text { de la esquina }\end{array}$ & Para facilitar la tarea del jugador del centro \\
\hline 9 & $\begin{array}{l}\text { Añadiendo cualquier instrumento de juegos } \\
\text { o deportes }\end{array}$ & $\begin{array}{l}\text { La finalidad sería incrementar el manejo con instrumentos como: } \\
\text { raquetas, palas, estics de hoquei, etc. }\end{array}$ \\
\hline \multicolumn{3}{|c|}{ Los participantes: compañeros y adversarios } \\
\hline IO & Añadiendo esquinas-participantes ${ }^{71}$ & Para incrementar las relaciones entre compañeros \\
\hline II & Disminuyendo una esquina-participante $^{7^{2}}$ & Para simplificar el juego, al mínimo de 4 jugadores \\
\hline I2 & $\begin{array}{l}\text { Incrementando los jugadores que ocupan } \\
\text { el centro }\end{array}$ & $\begin{array}{l}\text { En este caso habrá que ir aumentando también las esquinas. Estas } \\
\text { medidas incrementarán la complejidad del juego }\end{array}$ \\
\hline
\end{tabular}

69 Parlebas, P.: 200I, op. cit.; Parlebas, P.: 2003, op. cit.; Parlebas, P.: 2004, op. cit.

70 «Las cuatro esquinas», I86I, op. cit.

71 C. R.: 1847, op. cit.; FernándeZ, Á.: I851, op. cit.; GARcía, J.: 1858, op. cit.; «Las cuatro esquinas», I86I, op. cit.; «Las cuatro esquinas», I880, op. cit.; SANTos, Padre: I876, op. cit.

72 FernándeZ, F.: 1862, op. cit. 


\section{Los participantes: compañeros y adversarios}

I3 Duplicando, triplicando, cuadruplicando Para incrementar la complejidad del juego si se permite libertad de el espacio de juego -incluso llegando a i6 movimientos para todos los participantes esquinas-

I4 Actuando por parejas en cada esquina, co- Para incrementar la complejidad en la cooperación gidos de la mano

Is Actuando por parejas, como si fuesen uno Para incrementar la cooperación en la variante anterior. Hay que cosolo, sin cogerse de la mano

I6 Añadiendo participantes-adversarios municarse con el compañero cercano y con los de las otras esquinas

I7 Añadiendo una esquina vacía que hay que ocupar Añadiendo al juego algunos participantes que no ocupan esquina y solo tienen la función de dificultar el desplazamiento de cualquier otro participante

\begin{tabular}{|c|c|c|}
\hline & upar & $\begin{array}{l}\text { quina vacía. Para ellos, los jugadores deberán intentar anticipar los } \\
\text { movimientos de los del centro }\end{array}$ \\
\hline \multicolumn{3}{|c|}{ Variando la motricidad-desplazamiento } \\
\hline I8 & $\begin{array}{l}\text { Incrementando o reduciendo los puntos } \\
\text { de apoyo en bipedestación } \\
\text { 73 }\end{array}$ & Un punto de apoyo -a pata coja-, tres, cuatro, etc. \\
\hline I9 & Variando el modo de desplazamiento ${ }^{74}$ & Saltando, arrastrándose, girando -volteretas, giros- \\
\hline \multicolumn{3}{|c|}{ Variantes en la obligatoriedad de desplazamiento de los participantes } \\
\hline 20 & $\begin{array}{l}\text { Dando libertad a los participantes para } \\
\text { elegir los movimientos }\end{array}$ & $\begin{array}{l}\text { En este caso los jugadores son libres para elegir cuándo } \\
\text { quieren intercambiar las posiciones }\end{array}$ \\
\hline $2 \mathrm{I}$ & $\begin{array}{l}\text { Iniciando el desplazamiento mediante un } \\
\text { estímulo } 75\end{array}$ & $\begin{array}{l}\text { En este caso, a la señal, todos los jugadores tendrán que salir de su } \\
\text { esquina }\end{array}$ \\
\hline 22 & $\begin{array}{l}\text { Haciendo el desplazamiento solo con un } \\
\text { estímulo concreto }\end{array}$ & $\begin{array}{l}\text { Una persona externa al juego irá diciendo palabras. Solo una (o al- } \\
\text { gunas) palabras son las que determinarán el cambio de posiciones }\end{array}$ \\
\hline 23 & $\begin{array}{l}\text { Iniciando el desplazamiento en el dialo- } \\
\text { guillo inicial }\end{array}$ & $\begin{array}{l}\text { En este caso, los desplazamientos serán libres, pero se realizarán en } \\
\text { el momento del dialoguillo inicial del juego }\end{array}$ \\
\hline \multicolumn{3}{|c|}{ Variantes para el trabajo de contenidos históricos, matemáticos, geográficos, etc. ${ }^{76}$} \\
\hline 24 & $\begin{array}{l}\text { Añadiendo preguntas de contenidos ma- } \\
\text { temáticos, históricos, geográficos }\end{array}$ & $\begin{array}{l}\text { Con un jugador que fuera del juego propone los cambios. Cada } \\
\text { esquina sería un número, una ciudad, un hecho histórico... }\end{array}$ \\
\hline 25 & $\begin{array}{l}\text { Jugando a las cuatro esquinas-preguntas } \\
\text { geográficas }{ }^{77}\end{array}$ & $\begin{array}{l}\text { Propuesta de } \operatorname{García}^{78} \text {, compleja en la que el jugador del centro } \\
\text { propone preguntas sobre ciudades -extensión, número de habi- } \\
\text { tantes...- para que sean resultas. En caso de no responder bien, el } \\
\text { jugador que erró se sitúa en el centro }\end{array}$ \\
\hline 26 & Jugando a las cuatro esquinas-ciudades ${ }^{79}$ & $\begin{array}{l}\text { Propuesta de García }{ }^{80} \text { sencilla en la que cada jugador esquinero tie- } \\
\text { ne el nombre de una ciudad, y en el momento del cambio detalla } \\
\text { con qué ciudad se intercambia }\end{array}$ \\
\hline
\end{tabular}

73 Santos, Padre: 1876 , op. cit.

74 Amades, J.: 1983, op. cit.

75 FERnÁndez, F.: i862, op. cit.

${ }_{76}$ Con estas variantes, además de proponer un trabajo motriz, se potencian otros contenidos curriculares de otras materias.

77 GarcíA, J.: I858, op. cit.

${ }_{78}$ Ídem, ibidem.

79 Ídem, ibidem.

so Ídem, ibidem. 


\begin{tabular}{|c|c|c|}
\hline & MODIFICACIÓN LÚDICA & OBSERVACIONES \\
\hline \multicolumn{3}{|c|}{ Variantes para el trabajo de contenidos históricos, matemáticos, geográficos, etc. } \\
\hline 27 & $\begin{array}{l}\text { Adaptándolo a los puntos cardinales es- } \\
\text { quineros }\end{array}$ & $\begin{array}{l}\text { Adaptación del juego Los puntos cardinales }{ }^{8 \mathrm{gI}} \text {, pero transformándolo } \\
\text { en las cuatro (u ocho) esquinas }\end{array}$ \\
\hline 28 & $\begin{array}{l}\text { Proponiendo zonas de juego con nombres } \\
\text { o números }\end{array}$ & $\begin{array}{l}\text { En un terreno arenoso, añadiendo dibujos en cada zona y, según las } \\
\text { indicaciones, se limitarían unos movimientos y otros no }\end{array}$ \\
\hline 29 & Eliminando el desplazamiento & $\begin{array}{l}\text { Se podría eliminar el componente motriz, y jugar mediante un ta- } \\
\text { blero de ajedrez, con piedras o con algún pequeño móvil. En este } \\
\text { caso se harían preguntas y el jugador que fallase colocaría su ficha } \\
\text { en medio del tablero }\end{array}$ \\
\hline 30 & $\begin{array}{l}\text { Añadiendo una pregunta o afirmación en } \\
\text { el dialoguillo inicial }\end{array}$ & $\begin{array}{l}\text { Si se utiliza el dialoguillo inicial para empezar el juego, se pueden } \\
\text { hacer preguntas o afirmaciones que según la respuesta o su veraci- } \\
\text { dad impliquen (o no) el cambio de posiciones de los participantes } \\
\text { de las esquinas }\end{array}$ \\
\hline
\end{tabular}

\section{A modo de conclusión}

Es evidente la popularidad de las cuatro esquinas durante el s. XIX e inicios del xx. Elementos como la idoneidad del juego para ambos sexos -también conjuntamente-, juntamente con la posibilidad de practicarlo en cualquier momento del año -se podía jugar al interior o al exterior- o la posibilidad de añadir jugadores -añadiendo esquinas-, hicieron del juego un juego inclusivo. A esto hay que añadirle la no utilización del material como elemento beneficiador para esta popularidad, la sencillez de normas, el trabajo de la fuerza, la habilidad y la atención -y como consecuencia una óptima recreación higiénica en un período histórico con unos niveles de salud deplorables-.

Por lo tanto, se concluye que cinco son los elementos principales que permitieron esta popularidad: la posibilidad de jugarse en el interior y en el exterior; la posibilidad de que ambos sexos jugaran -tanto por separado, como conjuntamente-; la facilidad para añadir (incluso disminuir) jugadores, aumentando las esquinas; la no necesidad de material; y la sencillez normativa.

También destaca su carácter femenino, motivado, seguramente, por el contacto mínimo entre jugadores. Y su carácter saludable, en lo que se refiere al nivel de exigencia, la práctica de la carrera o los cambios de ritmo, fueron factores motivantes para que el juego gozase de esta familiaridad.

Asimismo, el juego analizado es una viva imagen de una sociedad cristiana con una clara separación entre sexos -y unos ideales de ocultar esta sexualidad-y que solo tiene algún momento de actuación conjunta, como es en el caso del juego, que, hay que decirlo, tiene que ser de no contacto o contacto bajo.

Podemos decir que, en la actualidad, aunque el juego aparezca en los libros, y sea más o menos conocido por los profesionales del deporte, no hay mucha popularidad por la práctica, excepto en casos concretos. Creemos, por lo tanto, que

8I Powell, B.: Juegos de explorador, Madrid, Tip. José Yagües, I9I4. 
su uso en las escuelas tiene que ser de utilidad para recuperar un juego olvidado, además de proporcionar diferentes beneficios a los practicantes. Y esta aparición escolar de bien seguro permitiría la interiorización de la actividad y el resurgimiento de una tradición por las plazas, parques y calles de pueblos y ciudades.

La recuperación de un juego popular-olvidado es necesaria, valorando su utilidad, funcionalidad y, en definitiva, práctica presente. Es decir, además de entender y hacer comprender el juego, hay que hacer valorar su simbolismo y significatividad, pero buscando el modo también de que la práctica se adapte a los nuevos tiempos, hecho que permitiría mantenerla alejada del olvido. Las propuestas de aplicación aportadas tienen este sentido y el juego se adapta a los nuevos tiempos, a los nuevos métodos pedagógicos y de entrenamiento, más globales y basados en el componente lúdico.

De este modo, añadiendo variantes, que de bien seguro muchas de ellas también se aplicaban en el pasado, el juego de las cuatro esquinas se adapta a los nuevos tiempos, a nuevas necesidades, y además queda enriquecido cognitiva y motrizmente.

A la vez, se recupera y refuerza uno de los muchos elementos de la cultura tradicional y se hace frente a un modelo pedagógico uniforme -acrítico y de desconocimiento de la tradición-, y que, en educación física, tiene en los deportes de masa su bastión. 
